\title{
Inhibition of Interleukin-8 Reduces Tumorigenesis of Human Non-Small Cell Lung Cancer in SCID Mice
}

\author{
Douglas A. Arenberg, ${ }^{\star}$ Steven L. Kunkel, ${ }^{\ddagger}$ Peter J. Polverini, ${ }^{\S}$ Mary Glass, ${ }^{\star}$ Marie D. Burdick, ${ }^{\star}$ and Robert M. Strieter \\ $*$ Departments of Internal Medicine (Division of Pulmonary and Critical Medicine) and ${ }^{\ddagger}$ Pathology, The University of Michigan Medical \\ School, Ann Arbor, Michigan 48109; and ${ }^{\S}$ The University of Michigan Dental School, Section of Oral Pathology, Ann Arbor, Michigan \\ 48109
}

\begin{abstract}
The salient feature of solid tumor growth is the strict dependence on local angiogenesis. We have previously demonstrated that IL-8 is an angiogenic factor present in freshly isolated specimens of human non-small cell lung cancer (NSCLC). Using a model of human NSCLC tumorigenesis in SCID mice, we now report that IL-8 acts as a promoter of human NSCLC tumor growth through its angiogenic properties. Passive immunization with neutralizing antibodies to IL-8 resulted in more than $40 \%$ reduction in tumor size and was associated with a decline in tumor-associated vascular density and angiogenic activity. IL-8 did not act as an autocrine growth factor for NSCLC proliferation. The reduction in primary tumor size in response to neutralizing antibodies to IL-8 was also accompanied by a trend toward a decrease in spontaneous metastasis to the lung. These data support the notion that IL-8 plays a significant role in mediating angiogenic activity during tumorigenesis of human NSCLC, thereby offering a potential target for immunotherapy against solid tumors. (J. Clin. Invest. 1996. 97:2792-2802.) Key words: angiogenesis • neovascularization • chemokines - cancer
\end{abstract}

\section{Introduction}

Lung cancer is the most common cause of cancer-related deaths in industrialized nations and clearly a significant public health problem (1). While the incidence of many other malignancies has declined or remained stable, the occurrence of bronchogenic carcinoma has escalated to near-epidemic proportions. In the United States, over 150,000 new cases of lung cancer are diagnosed with an equal number of deaths attributed to this disease each year (1). Despite effective strategies aimed at risk factor reduction (i.e., smoking cessation), the current trend in incidence of lung cancer is expected to continue well into the 21 st century, with a predicted mortality rate of 53.2 deaths per 100,000 population in the $1990 \mathrm{~s}$ (2). Al-

Address correspondence to Robert M. Strieter, M.D., Department of Internal Medicine, Division of Pulmonary and Critical Care, Box 0360, University of Michigan Medical Center, 3916 Taubman Drive, Ann Arbor, MI 48109-0360. Phone: 313-936-2612; FAX: 313-7644556; E-mail: rstrieter@uv1.im.med.umich.edu

Received for publication 21 September 1995 and accepted in revised form 2 April 1996.

J. Clin. Invest.

(C) The American Society for Clinical Investigation, Inc. 0021-9738/96/06/2792/11 \$2.00

Volume 97, Number 12, June 1996, 2792-2802 though intensive research into the biology and treatment of lung cancer has occurred over the last decade, current forms of therapy can only be expected to yield five year survival rates of less than $15 \%$ (2). Therefore, novel approaches to the treatment of lung cancer must be developed.

The pathobiology of lung cancer is complex, involving oncogenesis, tumorigenesis, evasion of host defenses, invasion, and metastasis (3). However, the salient feature of all solid tumor growth is the strict dependence on neovascularization. In the absence of local angiogenesis, tumors cannot grow beyond $2 \mathrm{~mm}^{3}$ (4-6). Folkman first proposed that tumors are angiogenesis dependent, with tumor growth requiring concomitant increases in vascular supply (5). Although there are a variety of putative mediators of angiogenesis, certain tumors have been found to produce factors which are directly angiogenic, while others may depend upon vascularization induced by products of responding inflammatory cells (7).

IL-8, a member of the CXC chemokine family, is a potent angiogenic factor (8-10). While IL-8 was initially discovered on the basis of chemotaxis and activation of neutrophils, our laboratory and others have found that IL- 8 in vitro has endothelial cell chemotactic activity and in vivo induces neovascularization in the cornea of rats and rabbits without leukocyte infiltration (8-10). The angiogenic activity of IL-8 is equivalent on a molar basis to other well recognized promoters of angiogenesis, such as basic fibroblast growth factor (bFGF $)^{1}(8)$, and is a significant angiogenic factor present in freshly isolated human non-small cell lung cancer (NSCLC), accounting for $42-80 \%$ of the overall angiogenic activity of these tumors (11).

In this study, we extended the previous observations to assess the role of IL- 8 in vivo during tumorigenesis of human NSCLC. A human NSCLC/SCID mouse chimera was employed by injecting the human NSCLC cell lines A549 (adenocarcinoma) and Calu 1 (squamous cell carcinoma) into the flanks of SCID mice. We demonstrated that tumor-derived IL-8 production directly correlated with the rate of growth of the two human NSCLC cells lines. IL- 8 was not found to behave as an autocrine growth factor for the proliferation of NSCLC cells. Moreover, when IL- 8 was depleted in vivo by a strategy of passive immunization with neutralizing antibodies, tumorigenesis was markedly reduced via a reduction in tumorassociated vascular density and angiogenic activity. These findings support the contention that IL-8 mediated angiogenesis is critical to tumorigenesis of human NSCLC.

1. Abbreviations used in this paper: ENA-78, epithelial neutrophil activating protein-78; FGF, fibroblast growth factor; GRO, growthrelated oncogene; IP-10, interferon- $\gamma$-inducible protein 10 ; NAP-2, neutrophil activating protein-2; NSCLC, non-small cell lung cancer; VEGF, vascular endothelial growth factor. 


\section{Methods}

Reagents. Polyclonal rabbit anti-human IL-8 sera was produced by immunization of rabbits with IL-8, (Peprotech, Rocky Hill, NJ) in multiple intradermal sites with complete Freund's adjuvant. This antibody has been previously well characterized for its neutralizing capacity $(8,9,11)$. The IL-8 anti-serum specificity has been confirmed by Western blot analysis against recombinant human IL-8 and was found to neutralize $30 \mathrm{ng}$ of IL-8 at a dilution of 1:1000 $(12,13)$. Furthermore, in a sandwich ELISA, this antibody is specific for IL-8 without cross-reactivity to a panel of 12 other recombinant human cytokines or the murine chemokines KC and MIP-2 $(13,14)$. A549 media consisted of RPMI-1640 (Whitaker Biomedical Products, Whitaker, CA), $1 \mathrm{mM}$ glutamine, $25 \mathrm{mM}$ Hepes buffer, $100 \mathrm{U} / \mathrm{ml}$ penicillin, and $100 \mathrm{ng} / \mathrm{ml}$ streptomycin and $10 \%$ fetal calf serum. Calu 1 media consisted of Eagle's minimal essential media (Whitaker Biomedical Products, Whitaker, CA) supplemented with $1 \mathrm{mM}$ glutamine, 25 $\mathrm{mM}$ Hepes buffer, $100 \mathrm{U} / \mathrm{ml}$ penicillin, $100 \mathrm{ng} / \mathrm{ml}$ streptomycin, and $10 \%$ fetal calf serum, $1 \%$ nonessential amino acids, and $1 \%$ sodium pyruvate. The "anti-protease" buffer for tissue homogenization consisted of $1 \times$ PBS with $2 \mathrm{mM}$ phenylmethylsulfonyl fluoride, and $1 \mu \mathrm{g} /$ $\mathrm{ml}$ each of antipan, aprotinin, leupeptin, and pepstatin A. The antiCD 49b antibodies used in the FACS ${ }^{\circledR}$ analysis of human VLA-2 were purchased from Pharmingen (San Diego, CA). Goat anti-Factor VIII related antigen antibodies were purchased from Biomeda (Foster City, CA).

Human NSCLC cell lines. The A549 and Calu 1 cell lines (American Type Culture Collection, Rockville, MD) were maintained in sterile $150-\mathrm{cm}^{2}$ tissue culture flasks. Cells were cultured and passaged at $37^{\circ} \mathrm{C}$ in room air $/ 5 \% \mathrm{CO}_{2}$. To determine the constitutive production of IL-8, A549, and Calu 1 cells were plated in 35-mm wells, grown to $85 \%$ confluence, washed, and serum free media replaced. Conditioned media were collected at $24,48,72$, and $96 \mathrm{~h}$, centrifuged at $900 \mathrm{~g}$ for $10 \mathrm{~min}$, and stored at $-20{ }^{\circ} \mathrm{C}$ until thawed for analysis by IL-8 ELISA. For proliferation assays, $5 \times 10^{4}$ cells were plated in 35$\mathrm{mm}$ wells and allowed to grow to $50 \%$ confluence, serum starved for $24 \mathrm{~h}$, then treated with either IL-8, control or neutralizing anti-IL-8 antibodies in the presence of complete media. Cells were then trypsinized, and counted on a hemocytometer. For inoculation into mice, the cells were trypsinized, harvested, washed, and resuspended in serum-free media.

Human NSCLC-SCID mouse chimeras. 4-6-wk-old female CB17SCID mice (Taconic Farms, Germantown, NY) with serum Ig $<1 \mu \mathrm{g}$ / $\mathrm{ml}$ were injected subcutaneously with human NSCLC cells $\left(1 \times 10^{6}\right.$ cells in $100 \mu \mathrm{l})$ into each flank. The animals were maintained under sterile conditions in laminar flow rooms and killed in groups of six. At time of death, anticoagulated (heparin $50 \mathrm{U} / 500 \mu \mathrm{l}$ of blood) blood was collected and centrifuged. The plasma was stored at $-70^{\circ} \mathrm{C}$ for later analysis. Tumors were dissected from the mice and measured with a Thorpe caliper (Biomedical Research Instruments, Rockville, $\mathrm{MD})$. A portion of the tumor was fixed in $4 \%$ paraformaldehyde for histologic analysis and immunohistochemistry. H \& E stained sections were examined under $400 \times$ magnification to quantify infiltrating neutrophils. 10 fields were examined in each of nine tumor sections from both anti-IL-8 and control antibody treated groups. Results were expressed as the number of cells per high power field (HPF; $400 \times$ ). The other portion of the tumor was snap frozen for subsequent homogenization and sonication in antiprotease buffer followed by filtration through $0.45-\mu \mathrm{m}$ filters (Acrodiscs, Gelman Sciences, Ann Arbor, MI). The filtrate was stored at $-70^{\circ} \mathrm{C}$ for later analysis of total protein and IL-8 by ELISA. All tumor homogenates were standardized for total protein prior to lyophilization (SpeedVac, Savant) and used in the corneal micropocket model of neovascularization. The right lung was inflated with $4 \%$ paraformaldehyde, and prepared for histopathologic analysis, or processed for FACS ${ }^{\circledR}$ analysis (CD49b) of human cell populations (A549 cells). In the IL-8 depletion studies, SCID mice received intraperitoneal (i.p.) injections of $500 \mu \mathrm{l}$ of either neutralizing rabbit anti-human IL-8, control (preim- mune) serum, or no treatment, every $48 \mathrm{~h}$ for $6 \mathrm{wk}$, starting at the time of cell inoculation. Tumor specimens from these mice were processed as described above.

Corneal micropocket model of angiogenesis. In vivo angiogenic activity of the tumors was assayed in the avascular cornea of Long Evans rat eyes, as previously described (15-17). Briefly, equal volumes of lyophilized tumor specimens normalized to total protein, were combined with sterile Hydron (Interferon Sciences Inc.) casting solution. $5-\mu l$ aliquots were pipetted onto the flat surface of an inverted sterile polypropylene specimen container, and polymerized overnight in a laminar flow hood under UV light. Prior to implantation, pellets were rehydrated with normal saline. Animals were given i.p. ketamine (150 $\mathrm{mg} / \mathrm{kg})$ and atropine $(250 \mu \mathrm{g} / \mathrm{kg})$ for anesthesia. Rat corneas were anesthetized with $0.5 \%$ proparacaine hydrochloride ophthalmic solution followed by implantation of the Hydron pellet into an intracorneal pocket (1-2 mm from the limbus). $6 \mathrm{~d}$ after implantation, animals received heparin $(1000 \mathrm{U})$ of and ketamine $(150 \mathrm{mg} / \mathrm{Kg})$ i.p., followed by a $10 \mathrm{ml}$ perfusion of colloidal carbon via the left ventricle. Corneas were harvested and photographed. Positive neovascularization responses were defined as sustained directional ingrowth of capillary sprouts and hairpin loops towards the implant were observed. Negative responses were defined as either no growth or only an occasional sprout or hairpin loop displaying no evidence of sustained growth.

Immunohistochemistry for interleukin-8. Tumor and lung specimens were fixed in $4 \%$ paraformaldehyde for $24 \mathrm{~h}$. Paraffin-embedded tissue sections were dewaxed with xylene and rehydrated through graded concentrations of ethanol. Samples were then stained for IL-8 using a modification of our previously described technique (14). Briefly, nonspecific binding sites were blocked with normal goat serum (BioGenex, San Ramon, California), washed, and overlaid with 1:1000 dilution of either control (rabbit) or rabbit anti-human IL-8 serum. Slides were then rinsed and overlaid with secondary biotinylated goat anti-rabbit $\operatorname{IgG}(1: 35)$ and incubated for $60 \mathrm{~min}$. After washing twice with Tris-buffered saline, slides were overlaid with a 1:35 dilution of alkaline phosphatase conjugated to streptavidin (BioGenex), and incubated for $60 \mathrm{~min}$. Fast Red (BioGenex) reagent was used for chromogenic localization of IL-8 antigen. After optimal color development, sections were immersed in sterile water, counterstained with Mayer's hematoxylin, and cover slipped using an aqueous mounting solution.

Quantitation of vessel density. Quantitation of vessel density was performed using a modification of the previously described method (18). Briefly, tissue sections were dewaxed with xylene and rehydrated through graded concentrations of ethanol. Slides were blocked with normal rabbit serum (BioGenex, San Ramon, California), and overlaid with 1:500 dilution of either control (goat) or goat anti-Factor VIII related antigen antibodies. Slides were then rinsed and overlaid with secondary biotinylated rabbit anti-goat $\operatorname{IgG}(1: 35)$ and incubated for $60 \mathrm{~min}$. After washing twice with Tris-buffered saline, slides were overlaid with a 1:35 dilution of alkaline phosphatase conjugated to streptavidin (BioGenex), and incubated for $60 \mathrm{~min}$. Fast Red (BioGenex) reagent was used for chromogenic localization of Factor VIII antigen. After optimal color development, sections were immersed in sterile water, counterstained with Mayer's hematoxylin, and cover slipped using an aqueous mounting solution. A549 tumor specimens from anti-IL-8 and control antibody treated SCID mice were examined in a blinded fashion for the presence of Factor VIII immunolocalization. Sections were first scanned at low magnification $(40 \times)$ to identify vascular "hot spots." Areas of greatest vessel density were then examined under higher magnification $(400 \times)$ and counted. Any distinct area of positive staining for Factor VIII was counted as a single vessel. Results were expressed as the mean number of vessels \pm SEM per high power field (HPF; $400 \times$ ). A total of $30 \mathrm{HPFs}$ were examined and counted from three tumors of each of the treatment groups.

IL-8 ELISA. Antigenic IL-8 was quantitated using a modification of a double ligand method as previously described $(13,14)$. 
Briefly, flat-bottomed 96-well microtiter plates (Nunc Immuno-Plate I 96-F) were coated with $50 \mu \mathrm{l} /$ well of the polyclonal anti-IL-8 (1 ng/ $\mu \mathrm{l}$ in $0.6 \mathrm{M} \mathrm{NaCl}, 0.26 \mathrm{M} \mathrm{H}_{3} \mathrm{BO}_{4}$, and $0.08 \mathrm{~N} \mathrm{NaOH}, \mathrm{pH}$ 9.6) for $24 \mathrm{~h}$ at $4^{\circ} \mathrm{C}$ and then washed with phosphate-buffered saline (PBS), $\mathrm{pH} 7.5$, $0.05 \%$ Tween-20 (wash buffer). Microtiter plate nonspecific binding sites were blocked with $2 \%$ BSA in PBS and incubated for $60 \mathrm{~min}$ at $37^{\circ} \mathrm{C}$. Plates were rinsed three times. $50 \mu \mathrm{l}$ of sample (neat, and 1:10) were added, followed by incubation for $1 \mathrm{~h}$ at $37^{\circ} \mathrm{C}$. Plates were washed three times, $50 \mu \mathrm{l} /$ well of biotinylated polyclonal rabbit antiIL-8 (3.5 ng/ $\mu$ l in PBS, pH 7.5, 0.05\% Tween-20, and 2\% FCS) added, and plates incubated for $45 \mathrm{~min}$ at $37^{\circ} \mathrm{C}$. Plates were washed three times, streptavidin-peroxidase conjugate (Bio-Rad Laboratories, Richmond, CA) added, and the plates incubated for $30 \mathrm{~min}$ at $37^{\circ} \mathrm{C}$. Plates were washed again and chromogen substrate (Bio-Rad Laboratories, Richmond, CA) added. The plates were incubated at room temperature to the desired extinction, and the reaction terminated with $50 \mu \mathrm{l} /$ well of $3 \mathrm{M} \mathrm{H}_{2} \mathrm{SO}_{4}$ solution. Plates were read at $490 \mathrm{~nm}$ in an automated microplate reader (Bio-Tek Instruments, Inc., Winooski, VT). Standards were dilutions of recombinant IL-8 from 100 $\mathrm{ng} / \mathrm{ml}$ to $1 \mathrm{pg} / \mathrm{ml}(50 \mu \mathrm{l} / \mathrm{well})$. This method consistently detected IL-8 concentrations greater than $50 \mathrm{pg} / \mathrm{ml}$ in a linear fashion. Tumor samples were run in parallel for total protein (TP) content (Pierce, Rockford, IL), and results were expressed as ng of IL-8 per mg total protein.

FACS analysis for human CD49b (A549 lung metastases). Before removal, lungs from human NSCLC tumor bearing animals were perfused with normal saline, and dissected free of the thoracic cavity. The right lung was minced, and incubated for $1 \mathrm{~h}$ in digestion media (RPMI with $0.02 \%$ collagenase type IV, and $0.1 \mathrm{mg}$ of bovine pancreas grade II DNaseI). Cells were further separated by repeatedly aspirating the cell suspension through a $20-\mathrm{ml}$ syringe. Cells were then pelleted at $600 \mathrm{~g}$ for $10 \mathrm{~min}$, resuspended in sterile water for $30 \mathrm{~s}$ to lyse remaining RBCs, washed in $1 \times$ PBS, and resuspended in complete media with $5 \%$ FCS. Cells were counted, transferred at a concentration of $5 \times 10^{6}$ cells $/ \mathrm{ml}$ to fluorescent antibody buffer ( $1 \% \mathrm{FA}$ buffer [Difco No. 2314-15], 1\% FCS, and 0.1\% azide), and maintained at $4^{\circ} \mathrm{C}$ for the remainder of the staining procedure. $100 \mu \mathrm{l}$ of cells were labeled with FITC conjugated rat anti-human CD49b (1 $\mu \mathrm{g}$ Pharmingen, San Diego, CA). This antibody recognizes the $\alpha_{2}$ portion of the $\beta_{1}$-integrin, VLA-2, a marker previously found to be expressed by A549 and Calu 1 cells (19). FITC-conjugated rat IgG was used as a control antibody. Unbound antibody was washed with FA buffer and the cell suspension was analyzed with FACS (Becton Dickinson). The data were expressed as the percentage of cells staining positively with anti-human CD49b.

Statistical analysis. The studies involved a minimum of six human NSCLC/SCID mouse chimeras at each time point or for each manipulation. Groups of data were evaluated by analysis of variance to indicate groups with significant differences. Data that appeared statistically significant were compared by Student's $t$ test for comparing the means of multiple groups, and were considered significant if $p$ values were less than 0.05 . Results were presented as means \pm SEM. Data was analyzed by Macintosh IIfx computer using Statview II statistical software package (Abacus Concepts, Inc.)

\section{Results}

Human NSCLC cell lines constitutively produce IL-8 that does not function as an autocrine growth factor. A549 and Calu 1 human NSCLC cell lines were cultured in a time-dependent manner. Conditioned media was harvested and assessed for the presence of IL- 8 by ELISA. Antigenic IL- 8 was produced in a temporal manner from both A549 and Calu 1 cells, with maximal levels of IL-8 seen at 96 h (Fig. 1). The A549 cells at $96 \mathrm{~h}$ were found to produce 5.6-fold greater levels of IL-8 than the Calu 1 cells $(122.0 \pm 10.1$ vs. $21.9 \pm 1.0 \mathrm{ng} / \mathrm{ml}, P=0.0002)$. To determine whether IL- 8 was an autocrine growth factor for

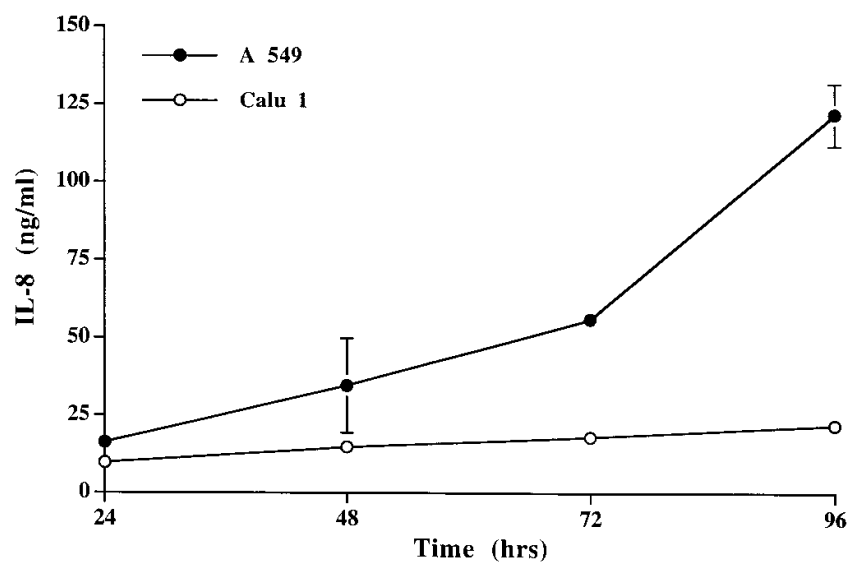

Figure 1. A549 and Calu 1 NSCLC cell lines constitutively produce IL-8 in vitro.

these cell lines, A549 and Calu 1 cells were cultured in the presence of either recombinant IL-8, neutralizing antibodies to IL-8, or control antibodies for 24 and $72 \mathrm{~h}$ (Table I). Neither the addition of exogenous IL-8, nor the neutralization of endogenous IL-8 altered cell proliferation, as compared to appropriate controls $(P>0.2)$. These findings suggested that human NSCLC cell lines constitutively produce IL-8 that does not function as an autocrine growth factor for cellular proliferation.

The production of $I L-8$ during tumorigenesis of human NSCLC in SCID mice directly correlates with tumor growth. While the above experiments suggested that IL-8 was constitutively produced by human NSCLC cells in vitro, we postulated that IL-8 may be acting in vivo to support tumorigenesis. To test this hypothesis, SCID mice were inoculated with either A549 or Calu 1 cells ( $10^{6}$ cells/flank) and killed weekly beginning with the second and third week of tumor growth, respectively. The experiments using A549 cells were terminated at 8 wk due to morbidity noted in the animals secondary to tumor

Table I. Analysis of In Vitro Proliferation of A549 and Calu 1 Cell Lines in the Presence of Either Exogenous IL-8, Neutralizing IL-8, or Control Antibodies

\begin{tabular}{lrc}
\hline & \multicolumn{2}{c}{ Time in culture } \\
\cline { 2 - 3 } & \multicolumn{1}{c}{$24 \mathrm{~h}$} \\
\cline { 2 - 3 } Conditions & \multicolumn{2}{c}{ Cells $\left(10^{4}\right.$ cells $)$} \\
\hline A549 & $71 \pm 11$ & $135 \pm 16.3$ \\
Control antibodies & $58 \pm 10$ & $148 \pm 10$ \\
IL-8 $(1 \mathrm{ng} / \mathrm{ml})$ & $72 \pm 15$ & $116 \pm 18$ \\
IL-8 $(10 \mathrm{ng} / \mathrm{ml})$ & $80 \pm 11$ & $144 \pm 7$ \\
anti-IL-8 antibodies & & \\
Calu 1 & $20 \pm 5.1$ & $39.3 \pm 4.7$ \\
Control antibodies & $12.7 \pm 1.2$ & $35.0 \pm 3.0$ \\
IL-8 $(1 \mathrm{ng} / \mathrm{ml})$ & $13.7 \pm 1.7$ & $25.3 \pm 3.0$ \\
IL-8 $(10 \mathrm{ng} / \mathrm{ml})$ & $15 \pm 3.6$ & $34.7 \pm 0.9$ \\
anti-IL-8 antibodies & & \\
\hline
\end{tabular}



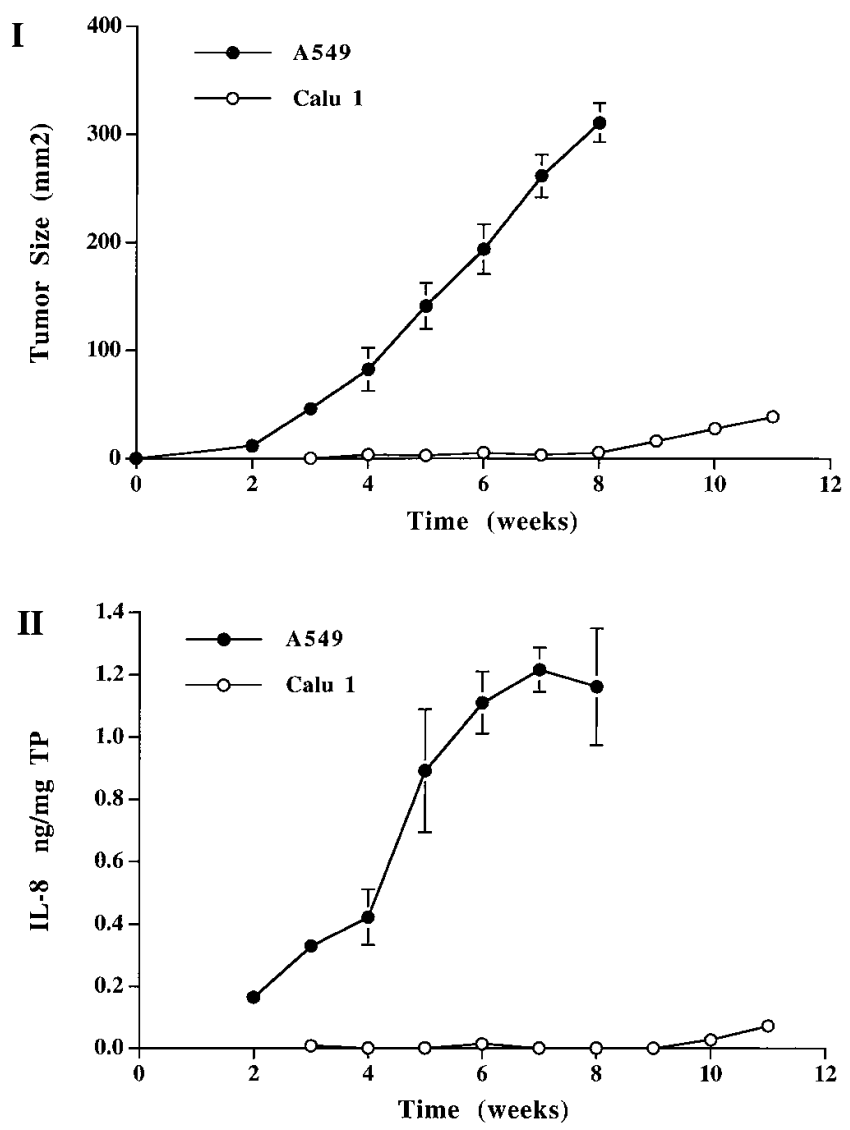

Figure 2. A549 and Calu 1 NSCLC tumor growth and IL-8 production in SCID mice. (I) The time course of tumor growth for A549 and Calu 1 NSCLC tumors. (II) The time course of A549 and Calu 1 tumor production of IL-8 normalized to total protein (TP).

burden. As shown in Fig. 2 I, there was a progressive increase in tumor size in A549 bearing animals beginning at weeks 2 through 8. In contrast, animals bearing Calu 1 tumors demonstrated little growth until week 8 (Fig. 2 I). The production of IL-8 from A549 tumors increased in direct correlation with tumor size $\left(r^{2}=0.90\right)$, and levels were maximal at $6-8 \mathrm{wk}$ of growth (Fig. $2 I I$ ). In contrast, the production of IL- 8 by Calu 1

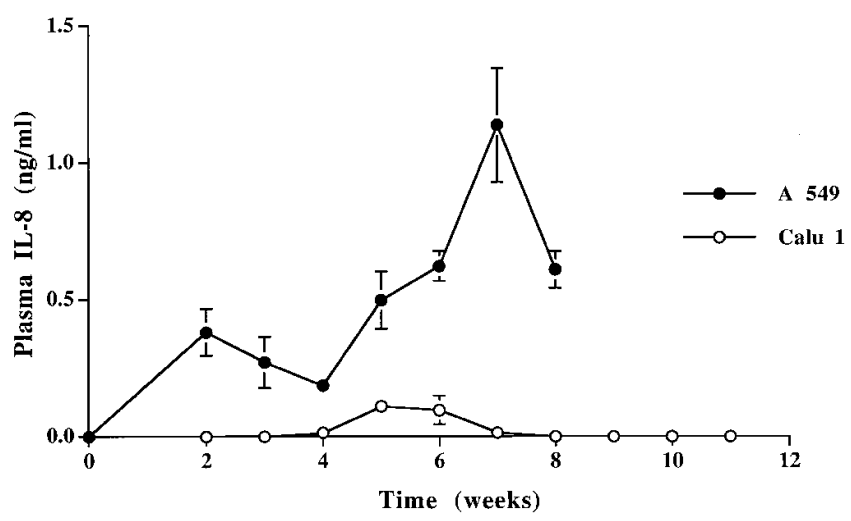

Figure 3. Circulating levels of plasma IL-8 from SCID mice bearing A549 or Calu 1 tumors. tumors was delayed, yet correlated with tumor size $\left(r^{2}=0.76\right)$ (Fig. $2 I I$; tumor $n=12$ ). The size of the A549 and Calu 1 tumors correlated highly with their mass $\left(r^{2}=0.91\right.$, data not shown). A549 (adenocarcinoma) tumors produced markedly greater levels of IL- $8(1.2 \pm 0.2 \mathrm{vs} . \sim 0 \mathrm{ng} / \mathrm{mg}$ total protein $)$ and were 50 -fold larger in size $\left(279 \pm 26\right.$ vs. $\left.5.6 \pm 1.4 \mathrm{~mm}^{2}\right)$ than Calu 1 (squamous cell carcinoma) tumors by 8 weeks (Fig. 2, I and II). Plasma levels of IL-8 from both A549 and Calu 1 tumor bearing animals paralleled the production of IL- 8 from the primary tumors and was maximal in A549 tumor bearing animals $(1.14 \pm 0.21 \mathrm{ng} / \mathrm{ml})$ at 7 weeks (Fig. 3). H\&E staining of A549 tumors demonstrated a paucity of infiltrating neutrophils (Fig. 4 I A). Immunohistochemistry of IL-8 within both the primary and metastatic (lung) A549 tumors localized to the tumor cells (Fig. 4, I $C$ and $I I C$, respectively). There was no evidence of nonspecific staining using the control antibodies in either the primary or metastatic tumors (Fig. $4, I B$ and $I I B$, respectively). These results demonstrate that the magnitude of IL- 8 production directly correlates with tumor growth and not with the tumor infiltration of leukocytes.

Neutralization of IL-8 during tumorigenesis of A549 tumors in SCID mice attenuates tumor growth. To delineate the role of IL-8 during tumorigenesis of A549 cells in SCID mice, animals were subjected to a strategy of IL- 8 depletion. SCID mice injected with A549 cells were treated at time of inoculation and every $48 \mathrm{~h}$ for a period of $6 \mathrm{wk}$ in one of the following ways. Passive immunization with neutralizing IL-8 antibodies, with control antibodies, or untreated. As illustrated in Fig. 5, I and II, A549 tumor bearing animals treated with neutralizing antibodies to IL- 8 demonstrated a $>40 \%$ reduction $(101 \pm 12.8$ $\mathrm{mm}^{2}$ ) in tumor growth at $6 \mathrm{wk}$, as compared with animals bearing A549 tumors that were either untreated $\left(193 \pm 20.7 \mathrm{~mm}^{2}\right)$ or treated with control antibodies $\left(173 \pm 23.7 \mathrm{~mm}^{2}\right.$, tumor $n=$ 12 in each group; $P<0.01$ for anti-IL- 8 treated vs. control antibody or untreated tumors). The degree of neutrophil infiltration in the tumors was small, with no significant difference noted between anti-IL- 8 treated mice $(3.2 \pm 0.4$ neutrophils per HPF) and control antibody treated mice ( $4.1 \pm 0.5$ neutrophils/HPF, $P=0.14$ ). IL-8 was undetectable by ELISA in the anti-IL-8 treated mice (data not shown). There was no significant difference in tumor size between the control antibody treated and untreated groups. Interestingly, using FACS analysis of human VLA-2 from the lungs of A549 tumor bearing mice, we found a trend toward a reduction in the number of metastatic cells in animals treated with neutralizing antibodies to IL-8 (Table II).

Neutralization of $I L-8$ reduces NSCLC angiogenic activity and vascularity. To further determine the mechanism of growth inhibition, we directly evaluated angiogenic activity from A549 tumors of animals that had been treated in vivo with either control or neutralizing anti-IL-8 antibodies for six weeks. The previously well-characterized corneal micropocket model in the rat was used (15-17). Tumor homogenates were normalized to total protein, incorporated into Hydron pellets, and embedded into the normally avascular rat cornea (Fig. 6). Five of the six A549 tumor samples from control antibody treated animals induced positive corneal angiogenic responses. In contrast, four of six A549 tumor samples from anti-IL-8 treated animals induced no corneal neovascular responses, with the remaining two inducing only weak angiogenic activity. Importantly, there was no infiltration of the corneal tissue by inflammatory cells in any of the test samples, suggesting that 

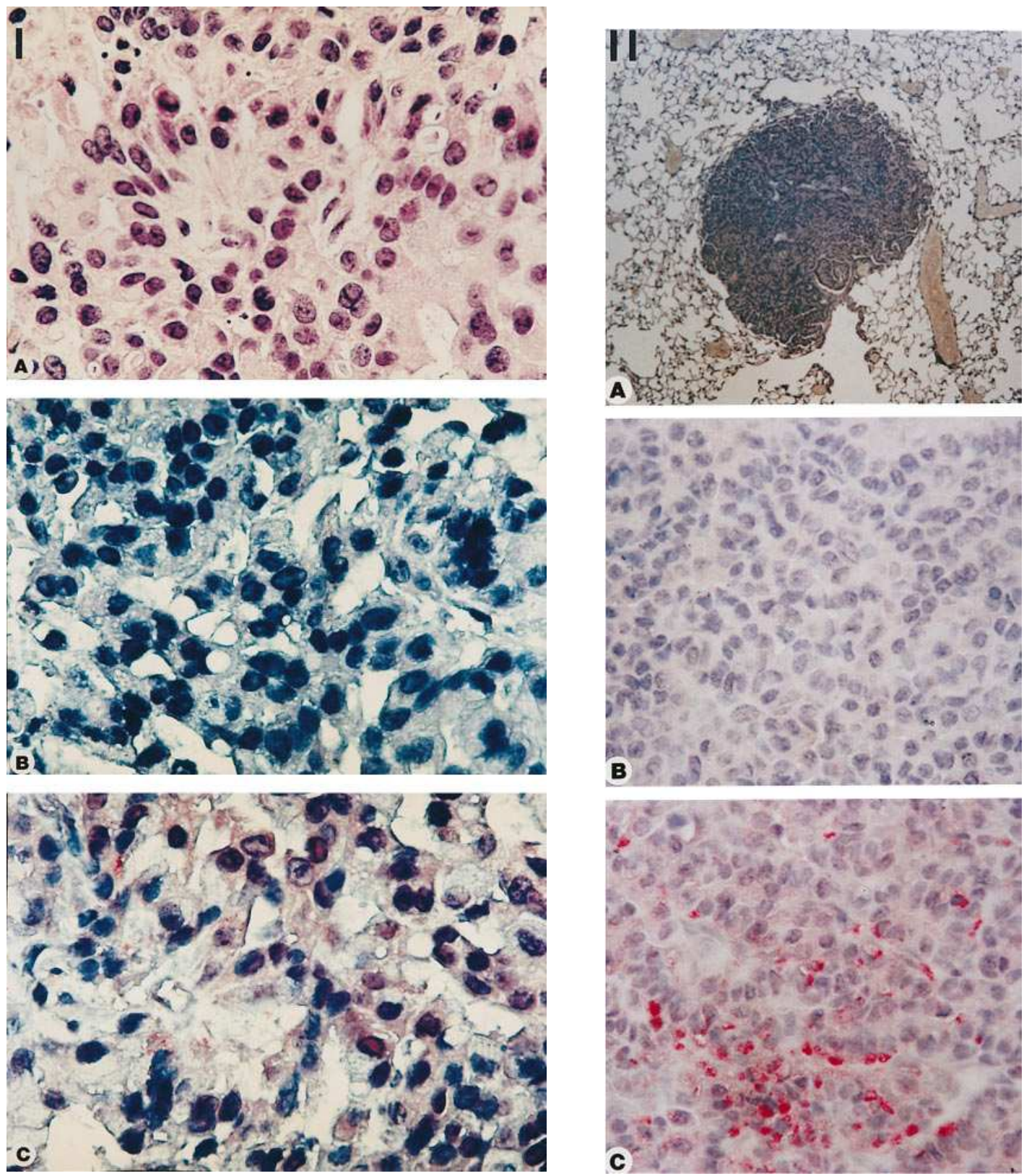

Figure 4. Immunohistochemistry of IL-8 in A549 primary and lung metastatic tumors in SCID mice at 8 wk. I, $A-C$ are the H \& E stained section of the primary tumor, control (preimmune antibodies) staining, and anti-IL- 8 staining, respectively (400 $\times$ ). II, $A-C$ are control (preimmune antibodies) staining $(40 \times)$, control $(400 \times)$, and immunolocalization of IL-8 $(400 \times)$, respectively, from an A549 metastatic lung tumor.

the angiogenic responses were mediated entirely by factors present in tumor tissue, rather than by products of infiltrating inflammatory cells. To further confirm that decreased angiogenic activity correlated with a reduction in tumor vascularity, vessel density was quantified from A549 tumors of SCID mice treated with either control or neutralizing IL-8 antibodies. A representative photomicrograph of Factor VIII immunolocalization of tumor vessels is shown in Fig. 7. Tumor vessel density in animals passively immunized with neutralizing IL-8 antibodies was significantly lower than in tumors of control antibody treated animals $(4.5 \pm 0.4$ vs. $10.7 \pm 0.4$ vessels per HPF, $P<0.0001$ ) (Table III). These studies demonstrated that a primary angiogenic signal for A549 tumor neovascularization in vivo was directly mediated by tumor-associated IL-8.

\section{Discussion}

IL-8 is a member of the CXC family of chemotactic cytokines. In monomeric forms the CXC chemokine family ranges in mass from $7-10 \mathrm{kD}$ and are characteristically basic, heparinbinding proteins. These chemokines display four highly con- 

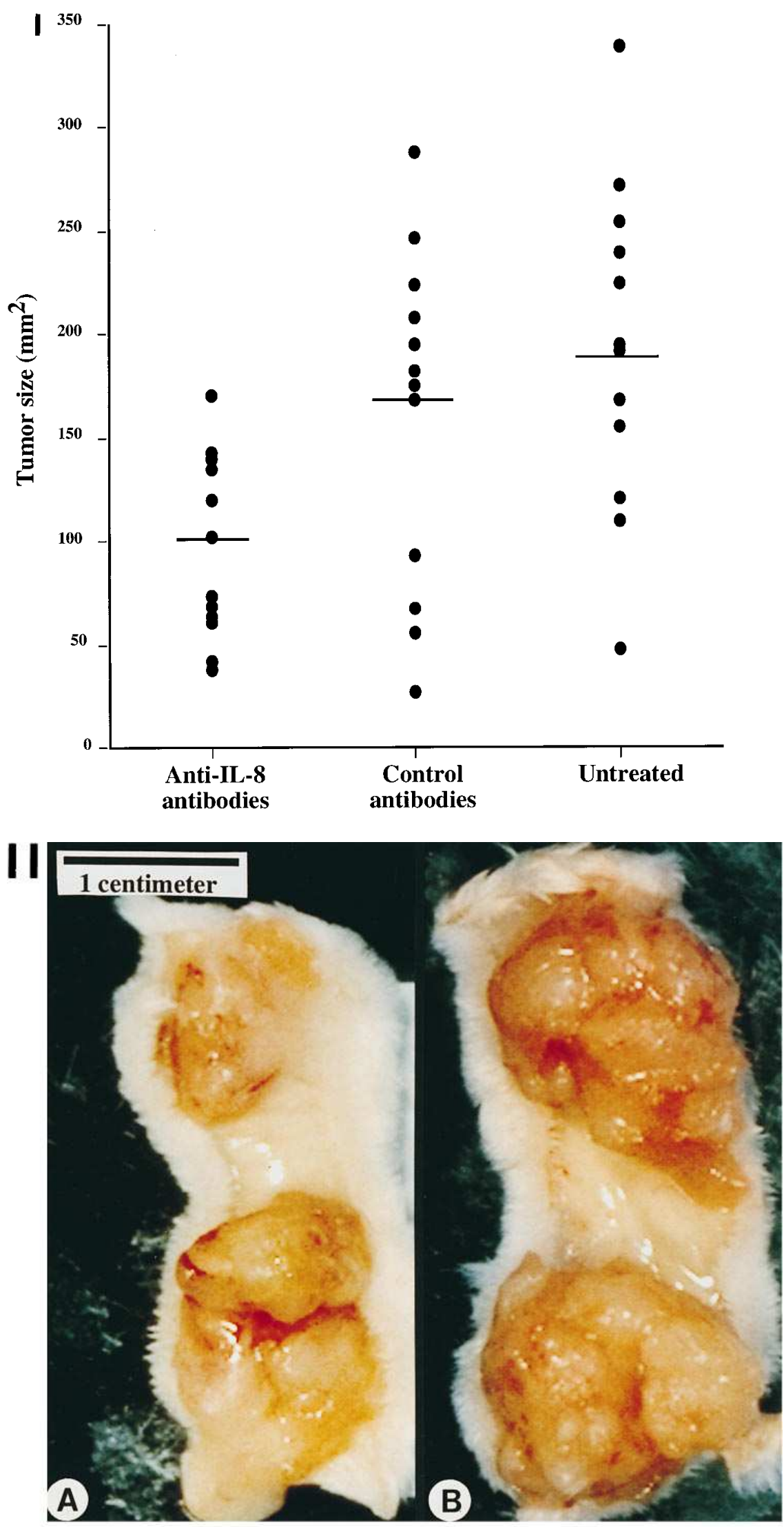

Figure 5. Neutralization of IL-8 during tumorigenesis of A549 tumors in SCID mice attenuates tumor growth. (I) A549 tumor size in SCID mice treated with either neutralizing anti-IL-8 antibodies, control (preimmune) antibodies, or untreated. (II) $A$ and $B$ are representative photographs of the gross A549 tumors from SCID mice treated with either neutralizing anti-IL-8 antibodies or control (preimmune) antibodies, respectively. 
Table II. FACS Analysis of Human CD49b in the Lungs of SCID Mice

\begin{tabular}{lc}
\hline \multicolumn{1}{c}{ Treatment conditions } & $\begin{array}{c}\text { Percent human } \\
\text { CD49b positive cells }\end{array}$ \\
\hline Normal lung (no tumor) & $1.3 \pm 0.5$ \\
Untreated & $15.2 \pm 8.9$ \\
Control antibodies & $11.6 \pm 1.0$ \\
Anti-IL-8 antibodies & $8.4 \pm 4.4$ \\
\hline
\end{tabular}

served cysteine amino acid residues, with the first two cysteines separated by a nonconserved amino acid residue. The CXC chemokines are all clustered on human chromosome 4 (q12-q21) and exhibit between 20 and 50\% homology on the amino acid level (20). Over the last two decades, in addition to IL-8, several human CXC chemokines have been identified and include platelet factor-4 (PF4), $\mathrm{NH}_{2}$-terminal truncated forms of platelet basic protein [connective tissue activating
protein-III (CTAP-III), beta-thromboglobulin ( $\beta$-TG), and neutrophil activating protein-2 (NAP-2)], growth-related oncogene alpha (GRO- $\alpha$ ), GRO- $\beta$, GRO- $\gamma$, interferon- $\gamma$-inducible protein 10 (IP-10), monokine induced by interferon- $\gamma$ (MIG), epithelial neutrophil activating protein-78 (ENA-78), and granulocyte chemotactic protein-2 (GCP-2) (21-23). The ubiquitous nature of IL-8 production by a variety of cells (14, 24-30) suggests that this chemokine may play a role in mediating biological events other than leukocyte chemotaxis.

Our laboratory and others have found that IL- 8 is a potent angiogenic factor (8-10). Recombinant IL-8 mediates both endothelial cell chemotactic and proliferative activity in vitro and angiogenic activity in vivo $(8,9)$. We found that IL-8-induced similar angiogenic activity as TNF- $\alpha$, aFGF, bFGF, angiogenin, angiotropin, and vascular endothelial cell growth factor (VEGF) $(8,31)$. Although a specific endothelial receptor(s) has not been discovered for the activity of IL-8-induced neovascularization, indirect evidence would suggest that the endothelial receptor for IL-8 is the IL-8 receptor B (IL-8RB). In support of this contention are the following findings: $(a)$ While endothelial cells have been found to express IL-8 recep-
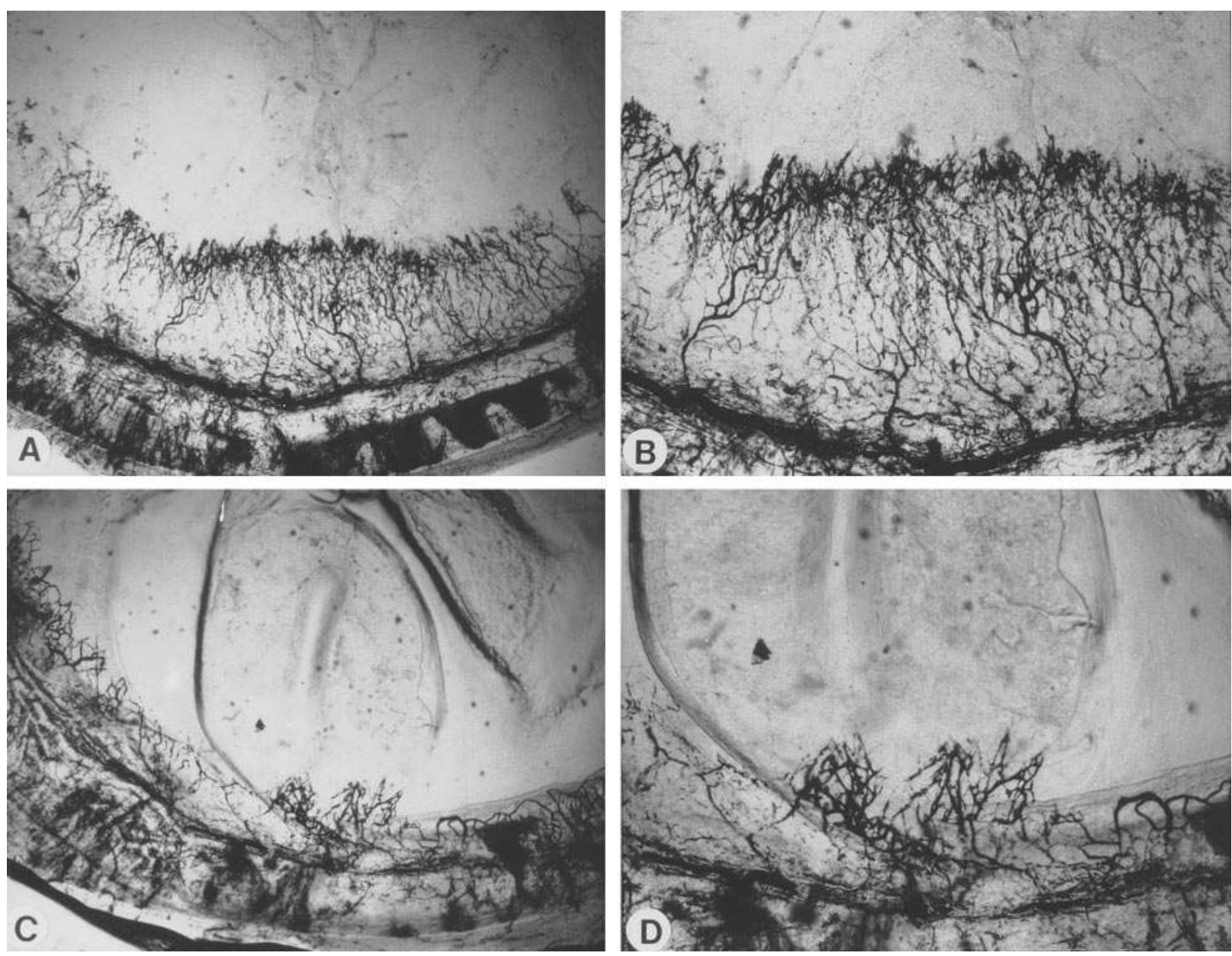

Figure 6. A representative $(n=6)$ photomicrograph of the corneal neovascular response to A549 tumors $(6$ wk) from SCID mice treated with either control (preimmune) antibodies or neutralizing anti-IL- 8 antibodies. $A$ and $B$ are $25 \times$ and $50 \times$ views, respectively, of corneas containing Hydron pellets of A549 tumor homogenates from SCID mice treated with control antibodies. $C$ and $D$ are $25 \times$ and $50 \times$ views, respectively, of corneas containing A549 tumor homogenates from SCID mice treated with neutralizing anti-IL-8 antibodies. All tumor homogenates were standardized to equivalent total protein before incorporation into Hydron pellet. 

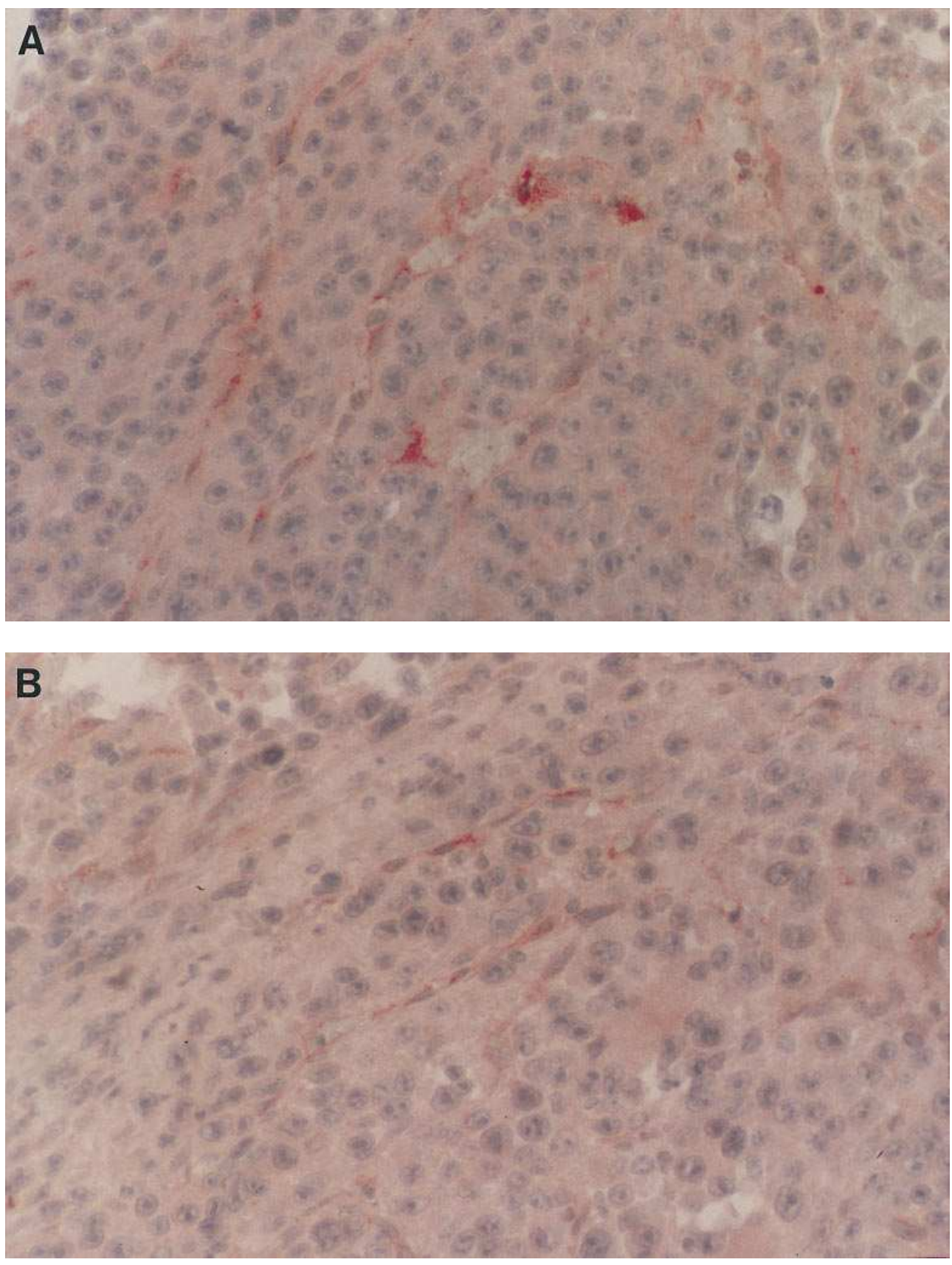

Figure 7. Representative photomicrographs $(400 \times)$ of Factor VIII stained microvessels from A549 tumors of SCID mice passively immunized with either control (preimmune) antibodies $(A)$ or neutralizing IL-8 antibodies $(B)$. tor A mRNA by RT-PCR, both IL-8 and NAP-2 could compete for binding on endothelial cells (32). However, only IL-8, not NAP-2, can bind to IL-8RA (33). (b) IL-8RB on neutrophils binds certain $\mathrm{CXC}$ chemokines (CXC chemokines bearing the Glu-Leu-Arg [ELR] motif immediately preceding the first cysteine amino acid residue of the primary sequence) with high affinity $(23,33,34)$, and we have found that all ELR-CXC chemokines are angiogenic (35). (c) While the Duffy antigen receptor for chemokines has been identified on post-capillary venule endothelial cells(36), this receptor binds not only ELRCXC chemokines, but also CC chemokines, monocyte chemoattractant protein-1 (MCP-1) and regulated on activation normal $\mathrm{T}$ cell expressed and secreted (RANTES) (36). We have found that these latter two $\mathrm{CC}$ chemokines are not chemotactic for endothelial cells (unpublished observations). (d) human burn tissue 2-12 d after injury has been found to express IL-8RB associated with capillary endothelial cells in areas of neovascularization(37). Nevertheless, further studies will be required to delineate the specific endothelial cell receptor(s) accounting for the angiogenic activities of IL-8 on both human and murine endothelium.

Previous studies have demonstrated that human neoplastic cell lines may directly elaborate IL-8 (14, 38-40). In addition, we have demonstrated significantly elevated levels of IL-8 from freshly isolated human NSCLC tumors that account for $42-80 \%$ of their angiogenic activity, as determined by bioassays of angiogenesis (11). This suggests that tumor production of this potent angiogenic factor may be crucial for the neovas- 
Table III. Tumor-derived Vascular Density as Assessed by Factor VIII Immunolocalization from Animals Passively Immunized with Either Neutralizing IL-8 or Control Antibodies

\begin{tabular}{lc}
\hline \multicolumn{1}{c}{ Treatment group } & $\begin{array}{c}\text { Tumor vessels } \\
\text { per HPF }(400 \times)\end{array}$ \\
\hline Anti-IL-8 antibodies & $4.5 \pm 0.4$ \\
Control antibodies & $10.7 \pm 0.4$ \\
\hline
\end{tabular}

Vessels were counted in 30 high power fields (HPF; 400×) from three tumors of each treatment group $(P=0.0001)$.

cularization necessary to initiate and maintain tumor growth. While this was the first demonstration that IL- 8 was a primary mediator of angiogenic activity in human NSCLC, these observations were limited by the fact that they were derived from examining tumors at a single point in time.

Despite the association of various angiogenic factors with diverse tumors, data on their temporal expression and contribution to tumor-derived angiogenic activity during tumorigenesis has not been fully elucidated. The human NSCLC/SCID mouse model provides the unique opportunity to examine the kinetics of human NSCLC tumorigenesis and metastasis in relation to the production of specific angiogenic factors. In this study, we demonstrated that two NSCLC cell lines, A549 (adenocarcinoma) and Calu 1 (squamous cell carcinoma), constitutively produce IL- 8 in vitro, and were found in vivo to generate IL-8 in a time-dependent manner that directly correlated with the rate of tumor growth. Immunohistochemistry demonstrated that IL-8 protein was localized to the human tumor cells, consistent with the inability of murine cells to produce IL-8, as well as the lack of cross-reactivity of our antibodies with murine homologues of CXC chemokines (13).

The paucity of neutrophil infiltration within the tumors, despite an appropriate chemotactic signal and the ability of murine neutrophils to respond to human IL-8 (41), remains perplexing. This lack of neutrophil infiltration in these tumors is similar to our previous observations of freshly isolated human NSCLC tumors (11). The relative absence of neutrophil infiltration in NSCLC may reflect the attenuation of inflammatory cell chemotactic signal by other tumor-derived factors. Our recent description of the production of interleukin-1 receptor antagonist and IL-10 by human NSCLC lends support to this concept $(42,43)$. Alternatively, the presence of IL-8 in circulation (plasma) of SCID mice that parallels the tumor production of IL-8, may simulate a phenomenon recently described in the IL-8 transgenic mouse (41). In this model, human IL-8 overexpression has been associated with increased circulating levels of IL-8, similar to what we have observed in the human NSCLC/SCID mice during tumorigenesis. These levels correlated with a proportional decrease in L-selectin expression (41). The IL-8 transgenic mice demonstrated a defect (50\% reduction) in neutrophil recruitment to the peritoneal cavity after intraperitoneal injection of either exogenous IL-8 or thioglycollate (41). While the IL-8 transgenic mouse model exemplifies the importance of localized production of IL-8 in order to establish a chemotactic gradient and target leukocytes to sites of inflammation, our study establishes a potential mechanism whereby the tumor may evade an innate host re- sponse by releasing sufficient IL- 8 into the circulation and attenuating neutrophil extravasation at the site of the tumor. Studies in our laboratories are currently addressing the mechanisms involved in these events.

These studies demonstrate that a significant angiogenic signal for human NSCLC neovascularization in association with tumorigenesis is directly mediated by tumor-associated IL-8. Several investigators have used histologic identification of microvessels to quantify vascular density within tumors and found that this correlated with prognosis and metastatic potential (44-46). When A549 tumor bearing animals were passively immunized with neutralizing IL-8 antibodies, we found a $58 \%$ reduction in tumor vascularity, as compared to control antibody treated mice. Additionally, we found that passive immunization with neutralizing IL-8 antibodies led to a reduction in tumor-derived angiogenic activity as assessed by the corneal neovascularization assay. The finding that IL-8 was not an autocrine growth factor for the NSCLC cell lines was important and further substantiated that the biological effect of IL-8 during tumorigenesis was due to promotion of angiogenesis and not cellular proliferation.

Interestingly, neutralization of IL-8 also resulted in a trend toward a reduction in spontaneous lung metastasis. Although these findings did not reach statistical significance, the results are in agreement with the observations of Singh and associates (47), who found that the expression of IL-8 mRNA correlated with the metastatic potential of melanoma cell lines. While IL-8 has been found to be an autocrine growth factor for melanoma cells (40), our results demonstrating the function of IL-8 as an angiogenic factor for human NSCLC cells would suggest an additional explanation for the promotion of metastases of melanoma cells. Characteristics of an ideal factor to facilitate tumorigenesis and metastasis would include the ability to induce autocrine and paracrine growth was well as neovascularization.

Although our studies support the role of IL-8 as an important angiogenic factor during tumorigenesis of human NSCLC, we were unable to fully inhibit the growth of NSCLC. Other members of the CXC chemokine family may be produced by human NSCLC cells that can function in mediating neovascularization. Interestingly, PF4, IP-10, and MIG, are three members of the $\mathrm{CXC}$ chemokine family that are angiostatic factors, while NAP-2, ENA-78, GCP-2, GRO- $\alpha, \beta$, and $\gamma$ are CXC chemokines that are angiogenic $(35,48-50)$. This suggests that members of the CXC chemokine family can function as either angiogenic or angiostatic factors in regulating neovascularization. A549 cells, in addition to IL-8, have previously been found to produce ENA-78, GRO- $\alpha$, and $\beta(51)$. Furthermore, in light of numerous molecules that can induce neovascularization, we can not exclude that other non-CXC chemokine angiogenic factors may contribute to angiogenesis during human NSCLC tumorigenesis. Kim and colleagues (52), have demonstrated that VEGF plays an important role as an angiogenic factor in supporting tumorigenesis of rhabdomyosarcoma, glioblastoma, and leiomyosarcoma cell lines in the nude mouse. However, similar to our findings with neutralizing anti-IL-8 antibodies, anti-VEGF antibodies did not fully suppress tumor growth in their model system.

In conclusion, our results support the notion that IL-8 is a pivotal mediator of tumor-mediated angiogenesis, and suggests that tumor production of this potent angiogenic factor may be crucial for the neovascularization necessary for the ini- 
tiation and maintenance of NSCLC tumor growth. These findings have implications for the ultimate development of specific and targeted novel therapy aimed at attenuating the production of IL-8 during tumorigenesis of NSCLC.

\section{Acknowledgments}

This work was supported in part by National Institutes of Health grants CA-66180, HL-50057, and 1P-50HL-46487 (R.M. Strieter), HL-39926 (P.J. Polverini), and HL-31693 and HL-35276 (S.L. Kunkel).

\section{References}

1. Garfinkel, A. 1991. Cancer statistics and trends. In American Cancer Society Textbook of Clinical Oncology. A.I. Holleb, D.J. Fink, and G.P. Murphy, editors. American Cancer Society, Atlanta, Georgia. 2-9.

2. Faber, L.P. 1991. Lung cancer. In American Cancer Society Textbook of Clinical Oncology. A. I. Holleb, D.J. Fink, and G.P. Murphy, editors. American Cancer Society, Atlanta, Georgia. 194-212.

3. Shields, P.G., and C.C. Harris. 1993. Genetic predisposition to cancer. In Lung Cancer. J.A. Roth, J.D. Cox, and W.K. Hong, editors. Blackwell Scientific Pub, Boston, Massachusetts. 3-19.

4. Folkman, J., and R. Cotran. 1976. Relation of vascular proliferation to tumor growth. Int. Rev. Exp. Pathol. 16:207-248.

5. Gimbrone, M.A., S.B. Leapman, R.S. Cotran, and J. Folkman. 1972. Tumor dormancy in vivo by prevention of neovascularization. J. Exp. Med. 136: 261-276.

6. Folkman, J., K. Watson, D. Ingber, and D. Hanahan. 1989. Induction of angiogenesis during the transition from hyperplasia to neoplasia. Nature (Lond.). 339:58-61.

7. Leek, R.D., A.L. Harris, and C.E. Lewis. 1994. Cytokine networks in solid human tumors: regulation of angiogenesis. J. Leukocyte Biol. 56 (4):423435 .

8. Koch, A.E., P.J. Polverini, S.L. Kunkel, L.A. Harlow, L.A. DiPietro, V.M. Elner, S.G. Elner, and R.M. Strieter. 1992. Interleukin-8 (IL-8) as a macrophage-derived mediator of angiogenesis. Science (Wash. DC). 258:1798-1801.

9. Strieter, R.M., S.L. Kunkel, V.M. Elner, C.L. Martonyl, A.E. Koch, P.J. Polverini, and S.G. Elner. 1992. Interleukin-8: A corneal factor that induces neovascularization. Am. J. Pathol. 141:1279-1284.

10. Hu, D.E., Y. Hori, and T.P.D. Fan. 1993. Interleukin-8 stimulates angiogenesis in rats. Inflammation. 17:135-143.

11. Smith, D.R., P.J. Polverini, S.L. Kunkel, M.B. Orringer, R.I. Whyte, M.D. Burdick, C.A. Wilke, and R. M. Strieter. 1994. Inhibition of IL-8 attenuates angiogenesis in bronchogenic carcinoma. J. Exp. Med. 179:1409-1415.

12. Strieter, R.M., S.H. Phan, H.J. Showell, D.G. Remick, J.P. Lynch, M. Genord, C. Raiford, M. Eskandari, R.M. Marks, and S.L. Kunkel. 1989. Monokine-induced neutrophil chemotactic factor gene expression in human fibroblasts. J. Biol. Chem. 264:10621-10626.

13. Bacon, K.B., J. Westwick, and R.D.R. Camp. 1989. Potent and specific inhibition of IL-8. IL-1alpha, and IL-1beta-induced in vitro human lymphocyte migration by calcium channel antagonists. Biochem. Biophy. Res. Comm. 165: 349-354

14. Standiford, T.J., S.L. Kunkel, M.A. Basha, S.W. Chensue, J.P.L. III, G.B. Toews, J. Westwick, and R.M. Strieter. 1990. Interleukin-8 gene expression by a pulmonary epithelial cell line: A model for cytokine networks in the lung. J. Clin. Invest. 86:1945-1953.

15. Koch, A.E., J. Burrows, M. Cho, P.J. Polverini, and J. Leibovich. 1991. Thiol-containing compounds inhibit the production of monocyte/macrophagederived angiogenic activity. Agents Actions. 34 (3-4):350-357.

16. Polverini, P.J., P.S. Cotran, M.A. Gimbrone, and E.R. Unanue. 1977. Activated macrophages induce vascular proliferation. Nature(Lond.). 269 (5631):804-806.

17. Koch, A.E., S.J. Leibovich, and P.J. Polverini. 1989. Stimulation of neovascularization by human rheumatoid synovial tissue macrophages. Arthritis Rheum. 29 (4):471-479.

18. Weidner, N. 1995. Intratumor microvessel density as a prognostic factor in cancer. Am. J. Pathol. 147 (1):9-19.

19. Mette, S.A., J. Pilewski, C.A. Buck, and S.M. Albelda. 1993. Distribution of integrin cell adhesion receptors on normal bronchial epithelial cells and lung cancer cells in vitro and in vivo. Am. J. Respir. Cell Mol. Biol. 8:562-572.

20. Oppenheim, J.J., O.C. Zachariae, N. Mukaida, and K. Matsushima. 1991. Properties of the novel proinflammatory supergene "intercrine" cytokine family. Annu. Rev. Immunol. 9:617-648.

21. Miller, M.D., and M.S. Krangel. 1992. Biology and biochemistry of the chemokines: a family of chemotactic and inflammatory cytokines. Crit. Rev. Immunol. 12:17-46.

22. Farber, J.M. 1993. HuMIG: a new member of the chemokine family of cytokines. Biochem. Biophys. Res. Comm. 192:223-230.

23. Proost, P., C.D. Wolf-Peeters, R. Conings, G. Opdenakker, A. Billiau, and J. VanDamme. 1993. Identification of a novel granulocyte chemotactic protein (GCP-1) from human tumor cells: in vitro and in vivo comparison with natural forms of GROa, IP-10, and IL-8. J. Immunol. 150:1000-1010.

24. Strieter, R.M., S.L. Kunkel, H.J. Showell, and R.M. Marks. 1988 Monokine-induced gene expression of human endothelial cell-derived neutrophil chemotactic factor. Biochem. Biophys. Res. Commun. 156:1340-1345.

25. Thornton, A.J., R.M. Strieter, I. Lindley, M. Baggiolini, and S.L. Kunkel. 1990. Cytokine-induced gene expression of a neutrophil chemotactic factor/interleukin-8 by human hepatocytes. J. Immunol. 144:2609-2613.

26. Elner, V.M., R.M. Strieter, S.G. Elner, M. Baggiolini, I. Lindley, and S.L. Kunkel. 1990. Neutrophil chemotactic factor (IL-8) gene expression by cytokine-treated retinal pigment epithelial cells. Am. J. Pathol. 136:745-750.

27. Brown, Z., R.M. Strieter, S.W. Chensue, P. Ceska, I. Lindley, G.H. Nield, S.L. Kunkel, and J. Westwick. 1991. Cytokine activated human mesangial cells generate the neutrophil chemoattractant - interleukin 8. Kidney Int. 40:86-90.

28. Rolfe, M.W., S.L. Kunkel, T.J. Standiford, S.W. Chensue, R.M. Allen, H.L. Evanoff, S.H. Phan, and R.M. Strieter. 1991. Pulmonary fibroblast expression of interleukin-8: a model for alveolar macrophage-derived cytokine networking. Am. J. Respir. Cell Mol. Biol. 5:493-501.

29. Nickoloff, B.J., G.D. Karabin, J.W.C.N. Barker, C.E. Griffiths, V. Sarma, R. Mitra, J.T. Elder, S. L. Kunkel, and V.M. Dixit. 1991. Cellular localization of interleukin-8 and its inducer, tumor necrosis factor-alpha in psoriasis. Am. J. Pathol. 138:129-140.

30. Strieter, R.M., K. Kasahara, R.M. Allen, T.J. Standiford, M.W. Rolfe, F.S. Becker, S.W. Chensue, and S.L. Kunkel. 1992. Cytokine-induced neutrophil-derived interleukin-8. Am. J. Pathol. 141:397-407.

31. Folkman, J., and M. Klagsbrun. 1987. Angiogenic factors. Science (Wash. DC). 235:442-447.

32. Schönbeck, U., E. Brandt, F. Petersen, H. Flad, and H. Loppnow. 1995. IL-8 specifically binds to endothelial but not to smooth muscle cells. J. Immunol. 154:2375-2383.

33. Moser, B., C. Schumacher, V. von Tschamer, I. Clark-Lewis, and M. Baggiolini. 1991. Neutrophil-activating peptide 2 and gro/melanoma growthstimulatory activity interact with neutrophil-activating peptide 1 /interleukin 8 receptors on human neutrophils. J. Biol. Chem. 266:10666-10671.

34. Lee, J., R. Horuk, G.C. Rice, G.L. Bennett, T. Camerato, and W.I. Wood. 1992. Characterization of two high affinity human interleukin-8 receptors. J. Biol. Chem. 267:16283-16287.

35. Strieter, R.M., P.J. Polverini, S.L. Kunkel, D.A. Arenberg, M.D. Burdick, J. Kasper, J. Dzuiba, J. Van Damme, A. Walz, D. Marriott, S.Y. Chan, S. Roczniak, and A.B. Shanafelt. 1995. The functional role of the 'ELR' motif in CXC chemokine-mediated angiogenesis. J. Biol. Chem. 270 (45):27348-27357.

36. Hadley, T.J., Z. Lu, K. Wasniowska, S.C. Peiper, J. Hesselgesser, and R. Horuk. 1994. Postcapillary venule endothelial cells in kidney express a multispecific chemokine receptor that is structurally and functionally identical to the erythroid isoform, which is the Duffy blood group antigen. J. Clin. Invest. 94: 985-991.

37. Nanney, L.B., S.G. Mueller, R. Bueno, S.C. Peiper, and A. Richmond. 1995. Distributions of melanoma growth stimulatory activity or growth-related gene and the interleukin-8 receptor type B in human wound repair. Am. J. Pathol. 147 (5):1248-1260.

38. Van Meir, E., M. Ceska, F. Effenberge, A. Walz, E. Grouzman, I. Desbaillets, K. Frei, A. Fontana, and N. de Tribolet. 1992. Interleukin-8 is produced in neoplastic and infectious diseases of the human central nervous system. Cancer Res. 52:4297-4305.

39. Abruzzo, L.V., A.J. Thornton, M. Liebert, H.B. Grossman, H. Evanoff, J. Westwick, R.M. Strieter, and S.L. Kunkel. 1992. Cytokine-induced gene expression of interleukin-8 in human transitional cell carcinomas and renal cell carcinomas. Am. J. Pathol. 140:365-373.

40. Schadendorf, D., A. Moller, B. Algermissen, M. Worm, M. Sticherling, and B.M. Czarnetzki. 1993. IL-8 produced by human malignant melanoma cells in vitro is an essential autocrine growth factor. J. Immunol. 153 (7):2667-2675.

41. Simonet, W.S., T.M. Hughes, H.Q. Nguyen, L.D. Trebasky, D.M. Danilenko, and E.S. Medlock. 1994. Long term impaired neutrophil migration in mice overexpressing human interleukin-8. J. Clin. Invest. 94:1310-1319.

42. Smith, D.R., S.L. Kunkel, T.J. Standiford, S.W. Chensue, M.W. Rolfe, M.B. Orringer, R.I. Whyte, M.D. Burdick, J.M. Danforth, A.R. Gilbert, and R.M. Strieter. 1993. The production of Interleukin-1 receptor antagonist by human bronchogenic carcinoma. Am. J. Pathol. 143:794-803.

43. Smith, D.R., S.L. Kunkel, M.D. Burdick, C.M. Wilke, M.B. Orringer, R.I. Whyte, and R.M. Strieter. 1994. Production of Interleukin-10 by human bronchogenic carcinoma. Am. J. Pathol. 145:18-25.

44. Macchiarini, P., G. Fontanini, M.J. Hardin, F. Squartini, and C.A. Angeletti. 1992. Relation of neovascularization to metastasis of non-small cell lung cancer. Lancet. 340:145-146.

45. Weidner, N., P.R. Carroll, J. Flax, W. Blumenfeld, and J. Folkman. 1993. Tumor angiogenesis correlates with metastasis in invasive prostate carcinoma. Am. J. Pathol. 143:401-409.

46. Weidner, N., J.P. Semple, W.R. Welch, and J. Folkman. 1991. Tumor 
angiogenesis and metastasis-correlation in invasive breast carcinoma. N. Engl. J. Med. 324:1-8.

47. Singh, R.K., M. Gutman, R. Radinsky, C.D. Bucana, and I.J. Fidler. 1994. Expression of interleukin 8 correlates with the metastatic potential of human melanoma cells in nude mice. Cancer Res. 54 (12):3242-3247.

48. Angiolillo, A.L., C. Sgadari, D.T. Taub, F. Liao, J.M. Farber, S. Maheshwari, H.K. Kleinman, G.H. Reaman, and G. Tosato. 1995. Human Interferon-inducible protein 10 is a potent inhibitor of angiogenesis in vivo. J. Exp. Med. 158:155-162.

49. Luster, A.D., S.M. Greenberg, and P. Leder. 1995. The IP-10 chemokine binds to a specific cell surface heparan sulfate shared with platelet factor 4 and inhibits endothelial cell proliferation. J. Exp. Med. 182:219-232.

50. Maione, T.E., G.S. Gray, J. Petro, A J. Hunt, A.L. Donner, S.I. Bauer, H.F. Carson, and R.J. Sharpe. 1990. Inhibition of angiogenesis by recombinant human platelet factor-4. Science (Wash. DC). 247:77-79.

51. Walz, A., R. Burgener, B. Car, M. Baggiolini, S.L. Kunkel, and R.M. Strieter. 1991. Structure and neutrophil-activating properties of a novel inflammatory peptide (ENA-78) with homology to interleukin-8. J. Exp. Med. 174: 1355-1362.

52. Kim, J.K., B. Li, J. Winer, M. Armanini, N. Gillett, H.S. Phillips, and N. Ferrara. 1993. Inhibition of vascular endothelial growth factor-induced angiogenesis suppresses tumor growth in vivo. Nature (Lond.). 362:841-844. 